\title{
New horizons for critical care in cardiac surgery
}

\author{
Yatin Mehta, Satish Kumar
}

Post cardiac surgery patients require intensive monitoring, judicious use of cardiovascular drugs, effective pain control, early mobilization, and intense respiratory care. In the last decade, off-pump coronary artery bypass surgery (OPCAB) that avoids the use of cardiopulmonary bypass (CPB) and aortic cannulation has evolved. ${ }^{1}$ With the advent of new instruments, multi vessel bypass is now performed on the beating heart. As compared with conventional coronary artery by pass graft surgery (CABG), OPCAB is associated with less inflammatory response, coagulation disorders, multiorgan dysfunction, postoperative atrial fibrillation, stroke,$^{1-3}$ shorter hospital stay, early hospital discharge ${ }^{3}$ and better operative mortality and outcome.

All this has changed intensive care requirements in these patients. Pulmonary artery catheter (PAC) for estimating preload and cardiac output (CO) for improving outcome is still doubtful. A multicentre study in the setting of non emergency coronary artery bypass graft surgery (CABG) concluded that, use of PAC was associated with an increased in hospital mortality, greater length of stay and higher total cost particularly in hospitals with low volume of PAC use. ${ }^{4}$

Transesophageal echocardiography (TEE) on the other hand can directly visualize volume status, identify the cause of hypotension, detect new regional wall motion abnormalities and provide a visual impression of the effect of specific management. It is noninvasive, can be repeated when required and provides better images than Transthoracic echocardiography ${ }^{5}$ but is not continuous,

\section{From:}

Dept. of Anaesthesiology and Critical Care, Escorts Heart Institute and Research Centre, Okhla Road, New Delhi - 110 025, India.

Correspondence:

Dr. Yatin Mehta, MD, DNB, FRCA, FAMS, Sr. Consultant \& Head,

Department of Anaesthesiology and Critical Care,

Escorts Heart Institute and Research Centre,

Okhla Road, New Delhi - 110 025, India.

E-mail: yatinmehta@hotmail.com unlike PAC. In a study on 126 post cardiac surgical patient who were hypotensive despite conventional (fluid and inotropes) measures TEE revealed valuable diagnostic information in $82 \%$ patients. $19 \%$ underwent exploration on the basis of TEE, and the time to establish diagnosis by TEE was $9.6 \pm 2.8$ min. ${ }^{5}$ Reichert et al ${ }^{6}$ had similar results.

Newer methods of minimally invasive $\mathrm{CO}$ estimation like lithium dilution ${ }^{7}$ are under evaluation. Studies have shown that pulse contour cardiac output measurement (PiCCO) is reliable for at least 8 hours after cardiac surgery. ${ }^{8}$ Ultrasonic methods to estimate cardiac output can be performed externally by placing a probe on the chest or internally by inserting a probe in the oesophagus i.e. Trans esophageal cardiac output (TECO). ${ }^{9}$ Judicious use of $\mathrm{PAC}$ in high-risk patients is still reasonable till we gather more evidence regarding other non-invasive methods of haemodynamic monitoring.

Early extubations that is within 6 hours of ICU arrival are now an accompaniment of fast track cardiac anesthesia for CABG and is easier in OPCAB. ${ }^{10}$ The incidence of ventilator-associated pneumonia (VAP) is directly proportional to duration of ventilation. ${ }^{11}$ Early extubation is associated with decrease in hospital complications, ICU and hospital stay, cost of surgery and nosocomial pneumonia. Prone position ventilation has been shown to improve oxygenation in post cardiac surgery hypoxemia not responding to other means. ${ }^{12}$ Nitric oxide (NO) is another modality, which has been used for ARDS or in right heart failure as a temporary measure. ${ }^{13}$

Respiratory physiotherapy is an essential part of postoperative care, but its usefulness for prevention of pulmonary complications remains unproved. ${ }^{14}$

Cardiac surgery is particularly painful due to sternotomy/thoracotomy. With the advent of minimally inva- 
sive surgery including robotic cardiac surgery adequate postoperative analgesia is mandatory. In addition to intermittent or continuous infusion of analgesics, patient controlled analgesia is also effective. Thoracic epidural analgesia (TEA) has been shown to provide intense postoperative analgesia, helps in early extubation, improves pulmonary function and improves distribution of coronary flow. ${ }^{15}$ In patients receiving TEA a high index of suspicion for epidural haematoma should be kept in mind if lower limb motor weakness develops in the ICU. ${ }^{16}$ Then, local anaesthetic should be stopped and early CT scan of the spine is recommended. The incidence of epidural haematoma is approximately 1: 150,000 and early diagnoses and surgical evacuation will prevent paraplegia. ${ }^{17}$

Subarachnoid morphine ${ }^{17}$ has also been successfully used for pain relief in the first 24-36 hours. The risk of epidural haematoma remains, though much less.

The incidence of deep vain thrombosis (DVT) and pulmonary embolism (PE) is low in cardiac surgery patients. A procoagulant state has been described following OPCAB and low dose heparin, low molecular weight heparin and early mobilization reduces the incidence of DVT and PE. ${ }^{18}$ Sequential compression devices have not been effective in reducing the incidence of DVT and PE. ${ }^{19}$

It has been shown that, acute renal failure (ARF) occurring post cardiac surgery is an independent risk for mortality and morbidity. ${ }^{20} \mathrm{~A}$ modest increase in creatinine that resolves within 48 to $72 \mathrm{hrs}$ is common. ARF occurs more frequently following valve surgery than $C A B G$. The duration of CPB is an important intraoperative risk factor for severe and sustained ARF, which occurs in approximately $2 \%$ of the patients. Low ejection fraction, hypovolaemia, use of aminolycosides, use of angiotensin converting enzymes inhibitors and use of nonsteroidial anti-inflammatory agents, can increase the risk of renal failure.

To prevent ARF in post-cardiac surgical patients, prerenal factors must be corrected. Haemodynamic monitoring is crucial for appropriate fluid therapy. In a prospective randomized study OPCABs were associated with less renal dysfunction. ${ }^{21}$ Renal dose dopamine has no role in prevention and treatment of $\mathrm{ARF}^{22}$ furthermore it may increase the incidence of adverse complications like cardiac arrhythmia and gut ischaemia. Early aspirin therapy has been shown to reduce the incidence of ARF, stroke and gut ischaemia in these patients. ${ }^{23}$ Once ARF is established, renal replacement therapy should be instituted early. Daily renal replacement therapy reduces ICU stay and mortality, which has remained $15 \%$ over last 20 years.

A recent report by Vanden Burgh ${ }^{24}$ has shown that intensive control of blood sugar in surgical ICU (mainly post cardiac surgical) reduces infection rate, ICU stay and mortality. Blood sugar should be maintained between $100-150 \mathrm{mg} / \mathrm{dl}$ with the help of insulin therapy.

Post-cardiac surgery, the incidence of major neurological complications is high $2.1 \% \cdot{ }^{25}$ The risk factors for the development of neurological complications are old age, atheroma in aorta, carotid artery stenosis, left atrial / left ventricular thrombus and atrial fibrillation. Cerebral infarct develops due to emboli from atheroma, intracavity clots. The manifestations are focal neurological deficit, coma and seizures. The most useful diagnostic modality is CT scan.

Avoidance of application of the aortic cross clamp and $\mathrm{CPB}$ are expected to reduce the incidence of stroke flowing OPCABs. ${ }^{3}$

A lot has been achieved, but still many issues need to be tackled. Infection control and left ventricular assist devices, better ventilator strategies, non invasive ventilation, control of bleeding and pain, prevention of hypothermia need to be studied in the critical care of cardiac surgical patients and strategies need to be evolved for India with its special socioeconomic concerns in mind.

\section{References}

1. Demaria RG, Carrier M, Fortier S, et al. Reduced mortality and stroke with off pump coronary artery bypass grafting surgery in octogenarians. Circulation 2002;106:15-0.

2. D'Alfonso A, Mariani MA, Amerini A, et al. Off pump coronary surgery improves in hospital and early outcomes in octogenarians. Ital Heart J 2004;5:197-204.

3. Hernadez F, Cohn WE, Baribean YR, et al. In hospital outcomes of off pump versus on pump coronary artery bypass procedures: A multicenter experience. Ann Thorac Surg 2001;72:1528-33.

4. Ramsay SD, Saint S, Sillwan SP, et al. Clinical and economic effects of pulmonary artery catheterization in a non-emergent 
coronary artery bypass graft surgery. J Cardiothroac Vasc Anesth 2000;14:113-8.

5. Wasir H, Mehta Y, Mishra YK, et al. Tranesophageal echocardiography in hypotensive post coronary bypass patients. Asian Cardiovasc Thorac Annals 2003;11:139-42.

6. Reichert CL, Visser CA, Koolen JJ, et al. Tran esophageal echocardiography in hypotensive patient after cardiac operations. Comparison with hemodynamic parameters. J Thorac Cardiovasc Surg 1992;104:321-6.

7. Kurita T, Morita K, Kato S, Kikura M, et al. Comparison of the accuracy of the lithium dilution technique with the thermo dilution technique for measurement of cardiac output. $\mathrm{Br} \mathrm{J}$ Anaesth 1997;79:770-5.

8. Combes A, Berneau JB, Luyt CE, Trouillet JL. Estimation of left ventricular systolic function by single transpulmonary thermodilution. Intensive Car Med 2004;30:1377-83.

9. Leone D, Servillo G, De Robertis E, Rossano F, Tufano R. Monitoring cardiac output: Esophageal Doppler vs. Thermo dilution. Minerva Anestesiol 1998;64:351-6.

10. Hawkes CA, Dhileepan S, Foxcroft D. Early extubation for adult cardiac surgical patients. Cochrane Database Syst Rev 2003;(4):CD003587.

11. Pawar M, Mehta Y, Khurana P, Chaudhary A, Kulkarni V, Trehan N. Ventilator Associated Pneumonia: Incidence, risk factors, outcome and microbiology. J Cardiothorac Vasc Anesth 2003;17:22-8.

12. Firodiya M, Mehta Y, Juneja R, Trehan N. Mechanical ventilation in the prone position: A strategy for acute respiratory failure after cardiac surgery. Ind Heart J 2001;53:83-6.

13. Soko J, Jacobs SE, Bohn D. Inhaled nitric oxide for acute hypoxic respiratory failure in children and adults: A metaanalysis.
Anesth Analg 2003;97:989-98.

14. Pasquina $P$, Tramer MR, Walder B. Prophylactic respiratory physiotherapy after cardiac surgery: Systematic review. BMJ 2003;327.

15. Stenseth R, Bjella L, Berg EM, et al. Effects of thoracic epidural analgesia on pulmonary function after coronary artery bypass surgery. Eur J Cardiothorac Surg 1991;10:859-65.

16. Vandermeulen EP, Van Aken $\mathrm{H}$, Vermylen J. Anticoagulant and spinal epidural anesthesia. Anesth Analg 1994;79:1165-77.

17. Mehta Y, Kulkarni V, Sharma KK, et al. Spinal (subarachnoid) morphine for off pump coronary artery bypass surgery. Heart Surg Forum S-17, June 2003.

18. Mariani MA, Gu YJ, Boonstra PW, et al. Procoagulant activity after off pump coronary operation is the current anticoagulation adequate? Ann Thorac Surg 1999;67:1370-5.

19. Sammas NW. Pulmonary embolus after CABG: A review of the literature. Clin Cardiol 2000;23:637-44.

20. Conlon PJ, Staford-Smith M, White WD, Newman MF, Kings S, Winn MP, et al. Acute renal failure following cardiac surgery. Nephrol dial Transplant 1999;14:158-62.

21. Ascione R, Lloyd CT, Underwood MJ, et al. On pump versus off pump coronary revascularisation. Evaluation of renal function. Ann Thorac Surg 68:493-8.

22. Kellum JA, Decker MJ. Use of dopamine in ARF; a meta analysis. Criti Care Med 2001;29:1526-31.

23. Mangano DT, Fuster V, Karzai W, Priebe H. Aspirin and mortality from coronary bypass surgery. N Eng J Med 2002;347:1309-17.

24. Van den Berghe G, Woulers P, Weekers F. Intensive insulin therapy in critically ill patients. N Eng J Med 2001;345:1359-67.

25. Murkin JM. Neurological injury after cardiac surgery. Annals of Cardiac Anesthesia 1998;1:2-14. 